\title{
Early induction of hepatic deiodinase type 1 inhibits hepatosteatosis during NAFLD progression
}

Eveline Bruinstroop ${ }^{1,2}$, Jin Zhou ${ }^{1}$, Madhulika Tripathi' ${ }^{1}$, Winifred W. Yau' ${ }^{1}$, Anita Boelen², Brijesh Kumar Singh ${ }^{1}$, Paul M. Yen ${ }^{1,3,4}$

${ }^{1}$ Laboratory of Hormonal Regulation, Cardiovascular and Metabolic Disorders, Duke-NUS Medical School, 8 College Road, Singapore 169857, '2Department of Endocrinology \& Metabolism, Amsterdam UMC, Meibergdreef 9, 1105 AZ Amsterdam, The Netherlands. ${ }^{3}$ Duke Molecular Physiology Institute, Duke University School of Medicine, 300 N Duke St, Durham, NC 27701, USA. ${ }^{4}$ Endocrinology, Diabetes, and Metabolism Division, Duke University School of Medicine, $300 \mathrm{~N}$ Duke St, Durham, NC 27701, USA.

Conflicts of interest: The authors have declared that no conflict of interest exists.

Corresponding author:

Eveline Bruinstroop

Department of Endocrinology \& Metabolism, K2-283

Amsterdam UMC, locatie AMC

Meibergdreef 9

1105 AZ Amsterdam

The Netherlands

+31 (0) 6-20816946

e.bruinstroop@amsterdamumc.nl 


\begin{abstract}
Objective - Non-alcoholic fatty liver disease (NAFLD) comprises a spectrum ranging from hepatosteatosis to progressive non-alcoholic steatohepatitis that can lead to cirrhosis. Humans with low levels of the prohormone thyroxine $\left(T_{4}\right)$ have a higher incidence of NAFLD and thyroid hormone treatment is very promising in all patients with NAFLD. Deiodinase 1 (Dio1) is a hepatic enzyme that converts $T_{4}$ to the bioactive $T_{3}$, and therefore regulates intracellular thyroid hormone availability in the liver. The role of this intracellular regulation was investigated during the progression of NAFLD.
\end{abstract}

Methods - We investigated intracellular thyroid hormone metabolism in two NAFLD models: wildtype mice fed Western diet with fructose and $L e p r^{\mathrm{db}}$ mice fed a methionine- and choline-deficient diet. AAV8-mediated liver-specific Dio1 knockdown was employed to investigate the role of Dio1 during the progression of NAFLD. Intrahepatic thyroid hormone levels, deiodinase activity and metabolic parameters were measured.

Results - Dio1 expression and activity were increased in the early stages of NAFLD and were associated with an increased $T_{3} / T_{4}$ ratio. Prevention of this increase by AAV8-mediated liverspecific Dio1 knockdown increased hepatic triglycerides and cholesterol as well as decreased pACC/ACC ratio and acylcarnitine levels suggesting there was lower $\beta$-oxidation. Dio1 siRNA KD in hepatic cells treated with fatty acids showed increased lipid accumulation and decreased oxidative phosphorylation.

Conclusion - Hepatic Dio1 gene expression was modulated by dietary conditions, increased during hepatosteatosis and early $\mathrm{NASH}$, and regulated hepatic triglyceride content. These early adaptations likely represent compensatory mechanisms to reduce hepatosteatosis and prevent NASH progression.

Keywords: Liver - Steatosis - Thyroid - NAFLD - Deiodinase - NASH 


\section{Introduction}

Non-alcoholic fatty liver disease (NAFLD) comprises a spectrum of disease ranging from simple steatosis in the liver to steatohepatitis (NASH) with inflammation and fibrosis. NAFLD affects approximately $25 \%$ of the adult population worldwide, and its rise has been associated with the recent pandemic of obesity and diabetes [1]. Currently, there are no approved drugs for the treatment of NAFLD so there is an urgent need for the development of new therapies. Recently, thyroid hormone $(\mathrm{TH})$ and $\mathrm{TH}$-analogs (thyromimetics) have shown to be effective therapies for hepatosteatosis and NASH [2-6]. However, the physiological basis of their effects on NAFLD are not well understood.

TH stimulates lipophagy, $\beta$-oxidation of fatty acids, and oxidative phosphorylation in the liver [4 7]. Previous studies showed that both hypothyroidism and thyroid hormone receptor $\beta$ mutations in mouse and man increase the risk of NAFLD [8 9]. Also, lower serum levels of prohormone thyroxine $\left(T_{4}\right)$, even within the normal range increase the prevalence of NAFLD [10]. However, serum levels of $\mathrm{T}_{4}$ are not the only factor determining intracellular concentrations of the bioactive triiodothyronine $\left(T_{3}\right)$ which binds to the nuclear hormone receptor $\beta$ (TR $\left.\beta\right)$ causing transcriptional activation of $T_{3}$ target genes. Intracellular concentrations of the prohormone $T_{4}$ and the bioactive form of $T H, T_{3}$, are tightly regulated by intracellular deiodinases. There are three deiodinases, deiodinase type1 (Dio1), deiodinase type 2 (Dio2) and deiodinase type 3 (Dio3), all selenoenzymes of which Dio1 and Dio3 are expressed in hepatocytes. Dio1 is responsible for outer and inner ring deiodination of thyroid hormone and thereby involved in $T_{3}$ production and $r T_{3}$ clearance. Dio3 regulates $T_{3}$ and $T_{4}$ conversion to the inert metabolites $\mathrm{T}_{2}$ and $\mathrm{rT}_{3}$ respectively. The expression of Dio1 is influenced by cytokines and nutritional status, and it is markedly up-regulated by $T_{3}$ [2 11]. Previously, low levels of Dio1 expression were found in the livers of mice after acute and chronic inflammation, as well 
bioRxiv preprint doi: https://doi.org/10.1101/2021.05.13.443791; this version posted May 14,2021 . The copyright holder for this preprint (which

was not certified by peer review) is the author/funder, who has granted bioRxiv a license to display the preprint in perpetuity. It is made available under aCC-BY-ND 4.0 International license.

as in patients with NASH [12 13]. In this study, we examined the role of intracellular regulation of thyroid hormone during the different phases of NAFLD progression. 


\section{Materials and Methods}

\subsection{General}

All mice were maintained according to the Guide for the Care and Use of Laboratory Animals [National Institutes of Health $(\mathrm{NIH})$ publication 1.0.0; revised 2011], and experiments were approved by the Singhealth Institutional Animal Care and Use Committee (2015/SHS/1104).

\subsection{Western diet and fructose model}

Ten-week-old male C57BI/6J mice were fed Western diet (D12079B; Research Diets), supplemented with 15\% weight/volume fructose (Sigma-Aldrich, 57-48-7) in drinking water for 8 or 16 weeks whereas control mice received normal chow and tap water for 16 weeks. [14]

\subsection{Lepr $^{d b}$ with MCD diet model}

Male BKS.Cg-Dock7m+/+LeprdbJ (db/db) mice (Jackson Laboratory 009659) at 12 weeks of age were fed a normal chow diet or a MCD (A02082002BRi, Research Diets) diet for 2, 4 and 8 weeks to produce NASH stages. C57BI/6J mice (NUSCARE C57BL/6 JInv) fed a normal chow diet served as control.

\subsection{Liver-specific Dio1 Knockdown}

Ten-week-old male C57BI/6J mice were injected via tail vein with AAV8-ALB-eGFP-mDio1shRNAmir or AAV8-ALB-eGFP-ctrl-shRNAmir (Lot 181231\#13, Vector biolabs) and fed with NCD for two weeks followed by Western diet with fructose in the drinking water or NCD for next 12 weeks. A small group of mice $(n=3)$ injected with the control shRNA were fed with NCD for reference purpose only and not used for statistical purposes.

\subsection{Cell culture}

AML12 cells were passaged in DMEM/F12 (cat. 11320-033), 10\% FBS and 1x pen/strep, insulin transferrin selenium. 24 hours after plating the cells a mix of oleic acid $0.6 \mathrm{M}$ and palmitic acid (OAPA) in the above media with $1 \%$ BSA as carrier or only $1 \%$ BSA was added for 24,48 and 36 hours. For siRNA transfection, AML12 cells were trypsinized, mixed with opti-MEM medium (Invitrogen, 31,985,070) containing Lipofectamine RNAimax (Invitrogen, 13,778,150) and Dio1 (ON-TARGET plus Mouse Dio1 (13370) siRNA SMARTPOOL (Dharmacon) or control siRNA (10 
$\mathrm{nM}$ ) according to the manufacturer's recommendations. 24 hours later OAPA was added for 24 hours. The neutral lipid was stained with fluorescent dye BODIPY 493/503 (5 $\mu \mathrm{g} / \mathrm{ml})$ for $10 \mathrm{~min}$. Oxygen consumption was measured at $37^{\circ} \mathrm{C}$ using an XF24 extracellular analyzer (Seahorse Bioscience Inc., North Billerica, MA, USA) [19].

\subsection{Analysis}

Triglyceride concentrations in the liver and serum (10010303; Cayman Chemical Company, Ann Arbor, MI) and total cholesterol (ab65390, abcam) were measured with colorimetric kits according to the manufacturer's instructions after chloroform/methanol lipid extraction. Total RNA isolation was performed using InviTrap Spin Universal RNA kit (Stratec Biomedical), and RT-qPCR was performed as described previously [19] using QuantiTect SYBR Green PCR kit (Table primers in supplementary methods). Liver TH concentrations ( $T_{4}$ and bioactive $T_{3}$ ) were measured by LCMS/MS. Deiodinase 1 (Dio1) and 3 (Dio3) activity was measured by conversion of ${ }^{125}$-labelled $\mathrm{rT}_{3}$ and $T_{3}$ respectively as previously described [12]. For western blot analysis, proteins were separated by SDS-PAGE under reducing conditions and transferred to nitrocellulose membranes. Membranes were blocked with $5 \%$ nonfat milk in phosphate-buffered saline with $0.1 \%$ Tween 20 (Sigma-Aldrich, P9416; PBST). The blots were incubated overnight at $4^{\circ} \mathrm{C}$ with primary antibodies. Immunoblot analysis was performed using an enhanced chemiluminescence procedure (GE Healthcare, RPN2106).

\subsection{Statistical analysis}

For the WDF model the groups were compared using a one-way ANOVA with a post-hoc Dunnett's multiple comparison test to establish significance between the groups. For the Lepr ${ }^{\text {db }}$ with MCD model the wildtype mice with a NCD diet were compared with the $L e p r^{d b}$ mice on a NCD diet with an unpaired t-test to establish the effect of the genotype. To investigate the effect of the MCD diet the $\operatorname{Lepr}^{\mathrm{db}}$ on a NCD diet and 2,4 and 8 weeks of MCD were compared with a one-way ANOVA with a post-hoc Dunnett's multiple comparison test to establish significance between the groups. Dio1LKD-WDF were compared to the control-WDF with an unpaired t-test. Data points smaller than $Q 1-1.5 \times \mid Q R$ or greater than $Q 3+1.5 \times \mid Q R$ were considered outliers and removed from 
further analysis. Prism 8 was used for statistical analysis. Data are represented in mean \pm SEM. Significance was established at $p<0.05$.

\section{Results and Discussion}

\subsection{Dio1 expression and intrahepatic TH concentrations in mice fed Western diet and fructose} $(W D F)$

To examine intrahepatic $\mathrm{TH}$ regulation during the progression of NAFLD, we employed two different NAFLD models to induce hepatosteatosis and NASH. In the first model, we fed mice a Western diet with 15\% fructose water (WDF) diet for 8 and 16 weeks to induce steatosis and earlystage NASH and compared them with mice fed normal chow diet (NCD) (Fig. 1A) [14]. We observed that hepatic $T_{4}$ decreased in mice fed WDF for $8(15.3 \mathrm{pmol} / \mathrm{g})$ and $16(15.1 \mathrm{pmol} / \mathrm{g})$ weeks compared to mice fed NCD (26.0 pmol/g) (Table 1). This decrease in hepatic $\mathrm{T}_{4}$ was not explained by decreased expression of the thyroid hormone transporters Mct8 and Mct10 as we found increased expression of both transporters in mice fed WDF for 8 weeks followed by a return at 16 weeks to levels similar to those in mice fed NCD (Table 1). In contrast to the prohormone $T_{4}$, hepatic $T_{3}$ was not significantly different in mice fed WDF for 8 weeks $(2.1 \mathrm{pmol} / \mathrm{g})$ and slightly decreased in mice fed WDF for 16 weeks $(1.7 \mathrm{pmol} / \mathrm{g})$ compared to mice fed with NCD $(2.7 \mathrm{pmol} / \mathrm{g})$ (Table 1). These data indicated intracellular regulation of $T_{3}$ levels were likely mediated by deiodinases.

We next examined Dio1 gene expression which is known to convert $T_{4}$ to $T_{3}$ in liver cells. Dio1 mRNA increased more than 2-fold at both 8 and 16 weeks (Fig. 1B) in WDF mice. When Dio1 activity was measured by the conversion of ${ }^{125}$-labelled $\mathrm{rT}_{3}$, it increased significantly and was most pronounced at WDF 8 weeks compared to NCD mice (Fig. 1C). Increased Dio1 activity was associated with increased $T_{3} / T_{4}$ ratio for all mice indicating that it regulated intrahepatic $T_{3}$ 
concentration (Fig. 1D). We also measured Dio3 mRNA and Dio3 activity, known to metabolize $\mathrm{T}_{3}$ to its inert metabolites, and found they were not significantly different in mice fed WDF vs. NCD (Table 1). To further examine Dio1 mRNA induction during hepatosteatosis, we treated the mouse hepatic cell line, AML12, with $0.6 \mathrm{M}$ oleic acid and $0.6 \mathrm{M}$ palmitic acid (OAPA), and observed increases in Dio1 mRNA expression at 24, 48, and 72 hours suggesting that this combination of saturated and monosaturated fatty acids could induce Dio1 mRNA expression acutely in a cell autonomous manner (Fig. 1E, F).

We then measured hepatic triglyceride content and found that it was increased more than 10fold in mice fed WDF for 8 and 16 weeks when compared to mice fed NCD (Fig. 1G). Hepatic tumor necrosis factor alpha (Tnfa) was slightly increased in mice fed WDF for 8 weeks and more than 3fold in mice fed WDF for 16 weeks (Fig. 1H). Alpha-1 type I collagen (Col1a1) mRNA was significantly increased in mice fed WDF for 16 weeks (Fig. 1I). These data suggested that mice fed WDF for 8 weeks had hepatosteatosis and slight inflammation whereas mice fed WDF for 16 weeks developed early-stage NASH with induction of inflammation and fibrosis marker mRNAs. These changes occurred in parallel with increased Dio1 mRNA expression and activity, and correlated with $T_{3} / T_{4}$ ratio. Taken together, these data suggested that although a previous report showed Dio1 decreased in late stage NASH [2], Dio1 gene expression and activity increased in hepatosteatosis and early-stage NASH to maintain intrahepatic T3 concentration.

\subsection{Dio1 expression and intrahepatic TH concentrations in Lepr ${ }^{d b}$ mice fed a methionine and choline} $\underline{\text { deficient diet }}$

To validate this observation in a second NAFLD model, we used Lepr ${ }^{\mathrm{db}}$ mice that previously were shown to develop severe steatosis with only mild inflammation when fed normal chow diet (NCD) [15]. To induce the NASH phenotype, Lepr ${ }^{\mathrm{db}}$ were switched after 12 weeks of age to a methionine- and choline-deficient diet (MCD) for 2, 4, and 8 weeks (Fig. 1J) [15]. Lepr ${ }^{\mathrm{db}}$ mice continued on NCD diet had hepatic $\mathrm{T}_{4}$ levels that were $42 \%$ lower than wild-type mice on NCD 
(Lepr $^{\mathrm{db}}$-NCD T $4: 17$ vs. control-NCD $29.11 \mathrm{pm} / \mathrm{g}$ ). In this model, increases of the thyroid hormone transporter Mct8 mRNA were found after 2 and 8 weeks in Lepr ${ }^{\mathrm{db}}$ mice fed MCD diet. Next, we investigated intrahepatic $\mathrm{T}_{3}$ which decreased only by $12 \%$ in Lepr $^{\mathrm{db}}-\mathrm{NCD}$ compared to control-NCD (T3: 1.99 vs. $2.25 \mathrm{pmol} / \mathrm{g}$ ). In this model we also observed an increase in Dio1 mRNA expression in steatotic livers (Lepr ${ }^{\mathrm{db}}-\mathrm{NCD}$ vs. control-NCD) (Fig. 1K). Dio1 mRNA decreased below basal level in Lepr ${ }^{\mathrm{db}}$ mice fed MCD for 4 and 8 weeks similar to NASH in rats previously observed by us [2]. The enzyme activity of Dio1 was positively correlated with the $T_{3} / T_{4}$ ratio (Fig. $\left.1 \mathrm{~L}\right)$ again showing a regulatory role of deiodinases in liver T3 availability.

Triglyceride content in livers from Lepr ${ }^{\mathrm{db}}-\mathrm{NCD}$ mice increased more than 4-fold compared to control-NCD (Fig. 1M). Triglyceride content further increased in Lepr ${ }^{\mathrm{db}}$ fed MCD for 2 and 4 weeks. Tnfa and Col1a1 mRNA were not significantly different in Lepr ${ }^{\mathrm{db}}-\mathrm{NCD}$ and control-NCD mice. However, there was increased Tnfa mRNA expression starting at 2 weeks and continuing to 6 weeks suggesting ongoing inflammation after the initiation of MCD (Fig. 1N). Col1a1 mRNA was increased more than two-fold at 2 and 4 weeks, and increased 16 -fold at 6 weeks (Fig. 1). These findings suggested that fibrosis associated with gene expression became more prominent in Lepr ${ }^{\mathrm{db}}$ mice fed MCD by 8 weeks. Taken together in this second NAFLD model also an early increase in Dio1 mRNA was observed associated with the $T_{3} / T_{4}$ ratio.

\subsection{Liver-specific Dio1 shRNA knockdown in mice fed WDF}

Since T3 stimulates fatty acid $\beta$-oxidation, we investigated whether Dio1 increases during hepatosteatosis and early-stage $\mathrm{NASH}$ were protective mechanisms to maintain intrahepatic $\mathrm{T}_{3}$ concentration in order to reduce triglyceride accumulation in the liver during nutritional overload. Accordingly, we prevented the early induction of Dio1 by liver-specific knockdown using shRNA against mouse Dio1 cloned under the control of mouse albumin promoter in an adeno-associated viral vector (AAV8-Albumin-eGFP-mDio1-shRNAmir). Two weeks after tail vein injection of shRNA, mice were started on WDF or NCD for 12 weeks before sacrifice (Fig. 2A). We observed that 
hepatic Dio1 mRNA and Dio1 activity decreased by decrease $72 \%$ and $66 \%$, respectively, in Dio1 KD mice fed WDF (Dio1LKD-WDF) compared to control mice fed WDF (control-WDF) (Fig. 2B). Control-WDF had increased body weight and fat mass compared to control mice fed NCD (controlNCD); however, there were no significant differences in body weight, fat mass measured by MRI, and food intake was similar for Dio1LKD-WDF and control-WDF mice (data not shown). Hepatic $\mathrm{T}_{4}$ levels were higher in Dio1LKD-WDF (40.6 pmol/g) than control-WDF as would be expected if Dio1 expression/activity were decreased (Table 2). Interestingly, hepatic $T_{3}$ concentrations were not significantly different among the three groups of mice. When we analyzed sera from the mice, we saw increased $T_{4}$ levels in Dio1LKD-WDF (72.4 nmol/l) compared to control-WDF (52.3 nmol/l). Previously, it was shown that whole body knockout of Dio1 increased serum $T_{4}$ [16]. Our data showed that reduced hepatic Dio1 expression and activity was sufficient to exert this effect in mice. Of note, serum $T_{3}$ levels were not significantly different among the three groups of mice. In this experiment we did not find any effect on expression of Mct8 and Mct10 mRNA levels (Table 2). Taken together, the Dio1LKD-WDF showed decreased Dio1 gene expression and Dio1 activity resulting in reduced metabolism of intrahepatic $T_{4}$ concentrations without any differences in body weight and food intake.

Dio1LKD-WDF showed increased hepatic triglyceride and cholesterol content compared with control-WDF (Fig 2 C,D). We next analyzed hepatic fatty acid metabolism and found Dio1LKDWDF had a lower pACC/ACC protein ratio than control-WDF (Fig. 2E) suggesting there was increased fatty acid synthesis and decreased $\beta$-oxidation of fatty acids. We performed metabolomics of hepatic acylcarnitines as a measure of fatty acid $\beta$-oxidation. In control-WDF mice vs. control-NCD mice, there was a pattern of decreased short chain acylcarnitines $(C 2, C 3, C 4, C 6)$ together with increased longer chain acylcarnitines (C10:1, C10:2, C12:1, C14:2) indicative of lower $\beta$-oxidation of fatty acids (Supplementary Figure 1). There was a further decrease in $\mathrm{C} 2 / \mathrm{C} 4$ ratio and C6 in Dio1LKD-WDF compared to control control-WDF. We only observed an increase of the very long acylcarnitine C22:5 (Fig 2. F-G). We further examined the effects of Dio1 KD by siRNA in vitro combined with OAPA treatment in AML12 cells. We measured fat content by BODIPY 
staining in KD cells and observed increased fat content compared to control cells (Fig.2 H,I). Additionally, Dio1 KD cells exhibited decreased oxidative consumption rate by Seahorse analysis, consistent with lower fatty acid $\beta$-oxidation (Fig. 2J).

Last, we noticed there was a trend towards increased hepatic expression of TNFa and Col1a1 mRNA expression in Dio1LKD-WDF vs. control-WDF (Fig. 2K, L). When Dio1LKD-WDF were sacrificed 12 weeks after diet change, there was wide variability in the group at this transitional stage with some mice showing evidence of inflammation and fibrosis gene expression. In contrast, in this experiment none of the control-NCD or control-WDF had any increases in Tnfa and Col1a1 mRNA at 12 weeks. Histology also showed increased fat droplets visible in Dio1LKD-WDF with increased ballooning of hepatocytes (Fig. 2M). Serum triglyceride, cholesterol and glucose levels were not significantly altered by Dio1LKD-WDF compared to control-WDF (data not shown).

\section{Conclusions}

Taken together, our study showed that blocking Dio1 induction increased hepatic triglyceride and cholesterol content, and caused a rapid progression towards NASH in several individual Dio1LKD-WDF mice. This finding may have important physiological ramifications and suggests that induction of Dio1 expression and activity in hepatosteatosis and early NASH may play a preventive role in NASH progression. Moreover, increased hepatic Dio1 in these early stages of NAFLD supports our previous observation that levothyroxine $\left(T_{4}\right)$ can be an effective treatment for hepatosteatosis since it can be converted to $T_{3}$ intrahepatically [2]. Also, it is possible that patients with less induction of Dio1 in the early stages of NAFLD may be at higher risk for developing hepatosteatosis and NASH more rapidly. Decreased Dio1 is observed in older age, certain medications such as propranolol and propylthiohuracil, and selenium deficiency. Recently the first loss-of-function human Dio1 mutation causing changes in thyroid hormone metabolism was described [17]. On the other hand, a Dio1 polymorphism had increased Dio 1 activity [18]. Thus, epigenetic and genetic factors could alter Dio1 expression and/or activity, and thus affect the risk for progression of NAFLD. In conclusion, our findings show that hepatic Dio1 expression 
is sensitive to nutritional conditions and serves as a metabolic regulator during NAFLD progression to help decrease hepatosteatosis in early $\mathrm{NASH}$.

\section{Author contributions}

Eveline Bruinstroop: Conceptualization, Methodology, Formal analysis, Investigation, Writing Original Draft, Funding acquisition Jin Zhou: Conceptualization, Methodology, Investigation, Writing - Review \& Editing Madhulika Tripathi: Investigation, Writing - Review \& Editing Winifred W. Yau: Investigation, Writing - Review \& Editing Anita Boelen: Conceptualization, Investigation, Writing - Review \& Editing Brijesh Kumar Singh: Conceptualization, Methodology, Investigation, Supervision, Writing - Original Draft Paul M. Yen: Conceptualization, Methodology, Supervision, Writing - Original Draft, Funding acquisition.

\section{Acknowledgments}

The authors would like to acknowledge Jia Pei, Keziah Tikno and An de Ruiter for their technical assistance and Eric Fliers for his critical appraisal of the manuscript. E.B. was funded by a Khoo Postdoctoral Fellowship Award, Niels Stensen Fellowship, Ter Meulen Grant of the Royal Netherlands Academy of Arts and Sciences, and Catherine van Tussenbroekfonds (A3-2). The authors would also like to acknowledge the funding from National Medical Research Council, Ministry of Health and A*STAR Singapore NMRC/OFYIRG/0002/2016 and MOH-000319 to B.K.S.; NMRC/OFYIRG/077/2018 to M.T.; and Clinician Scientist Award MOH-000306 to P.M.Y. The funding source had no involvement in study design; in the collection, analysis and interpretation of data; in the writing of the report; and in the decision to submit the article for publication.

\section{References}

1. Younossi ZM, Koenig AB, Abdelatif D, Fazel Y, Henry L, Wymer M. Global epidemiology of nonalcoholic fatty liver disease-Meta-analytic assessment of prevalence, incidence, and outcomes. Hepatology 2016;64(1):73-84

2. Bruinstroop E, Dalan R, Cao Y, et al. Low-Dose Levothyroxine Reduces Intrahepatic Lipid Content in Patients With Type 2 Diabetes Mellitus and NAFLD. J Clin Endocrinol Metab 2018;103(7):2698-706 
3. Harrison SA, Bashir MR, Guy CD, et al. Resmetirom (MGL-3196) for the treatment of nonalcoholic steatohepatitis: a multicentre, randomised, double-blind, placebo-controlled, phase 2 trial. Lancet 2019;394(10213):2012-24

4. Sinha RA, Bruinstroop E, Singh BK, Yen PM. Nonalcoholic Fatty Liver Disease and Hypercholesterolemia: Roles of Thyroid Hormones, Metabolites, and Agonists. Thyroid 2019;29(9):1173-91

5. Cable EE, Finn PD, Stebbins JW, et al. Reduction of hepatic steatosis in rats and mice after treatment with a liver-targeted thyroid hormone receptor agonist. Hepatology 2009;49(2):407-17

6. Finan B, Parlee SD, Yang B. Nuclear hormone and peptide hormone therapeutics for NAFLD and NASH. Mol Metab 2020:101153

7. Sinha RA, You SH, Zhou J, et al. Thyroid hormone stimulates hepatic lipid catabolism via activation of autophagy. J Clin Invest 2012;122(7):2428-38

8. Chaves C, Bruinstroop E, Refetoff S, Yen PM, Anselmo JD. INCREASED HEPATIC FAT CONTENT IN PATIENTS WITH RESISTANCE TO THYROID HORMONE BETA. Thyroid 2020

9. Araki O, Ying H, Zhu XG, Willingham MC, Cheng SY. Distinct dysregulation of lipid metabolism by unliganded thyroid hormone receptor isoforms. Mol Endocrinol 2009;23(3):308-15

10. Xu C, Xu L, Yu C, Miao M, Li Y. Association between thyroid function and nonalcoholic fatty liver disease in euthyroid elderly Chinese. Clin Endocrinol (Oxf) 2011;75(2):240-6

11. Liu J, Hernandez-Ono A, Graham MJ, Galton VA, Ginsberg HN. Type 1 Deiodinase Regulates ApoA-I Gene Expression and ApoA-I Synthesis Independent of Thyroid Hormone Signaling. Arterioscler Thromb Vasc Biol 2016;36(7):1356-66

12. Boelen $A$, van der Spek AH, Bloise $F$, et al. Tissue thyroid hormone metabolism is differentially regulated during illness in mice. J Endocrinol 2017;233(1):25-36

13. Bohinc BN, Michelotti G, Xie G, et al. Repair-related activation of hedgehog signaling in stromal cells promotes intrahepatic hypothyroidism. Endocrinology 2014;155(11):4591601

14. Widjaja AA, Singh BK, Adami E, et al. Inhibiting Interleukin 11 Signaling Reduces Hepatocyte Death and Liver Fibrosis, Inflammation, and Steatosis in Mouse Models of Nonalcoholic Steatohepatitis. Gastroenterology 2019;157(3):777-92.e14

15. Witek RP, Stone WC, Karaca FG, et al. Pan-caspase inhibitor VX-166 reduces fibrosis in an animal model of nonalcoholic steatohepatitis. Hepatology 2009;50(5):1421-30

16. Schneider MJ, Fiering SN, Thai B, et al. Targeted disruption of the type 1 selenodeiodinase gene (Dio1) results in marked changes in thyroid hormone economy in mice. Endocrinology 2006;147(1):580-9

17. França MM, German A, Fernandes GW, et al. Human Type 1 lodothyronine Deiodinase (DIO1) Mutations Cause Abnormal Thyroid Hormone Metabolism. Thyroid 2020

18. Panicker V, Cluett C, Shields B, et al. A common variation in deiodinase 1 gene DIO1 is associated with the relative levels of free thyroxine and triiodothyronine. J Clin Endocrinol Metab 2008;93(8):3075-81

19. Singh BK, Sinha RA, Zhou J, et al. Hepatic FOXO1 Target Genes Are Co-regulated by Thyroid Hormone via RICTOR Protein Deacetylation and MTORC2-AKT Protein Inhibition. J Biol Chem 2016;291(1):198-214 


\section{Figures}
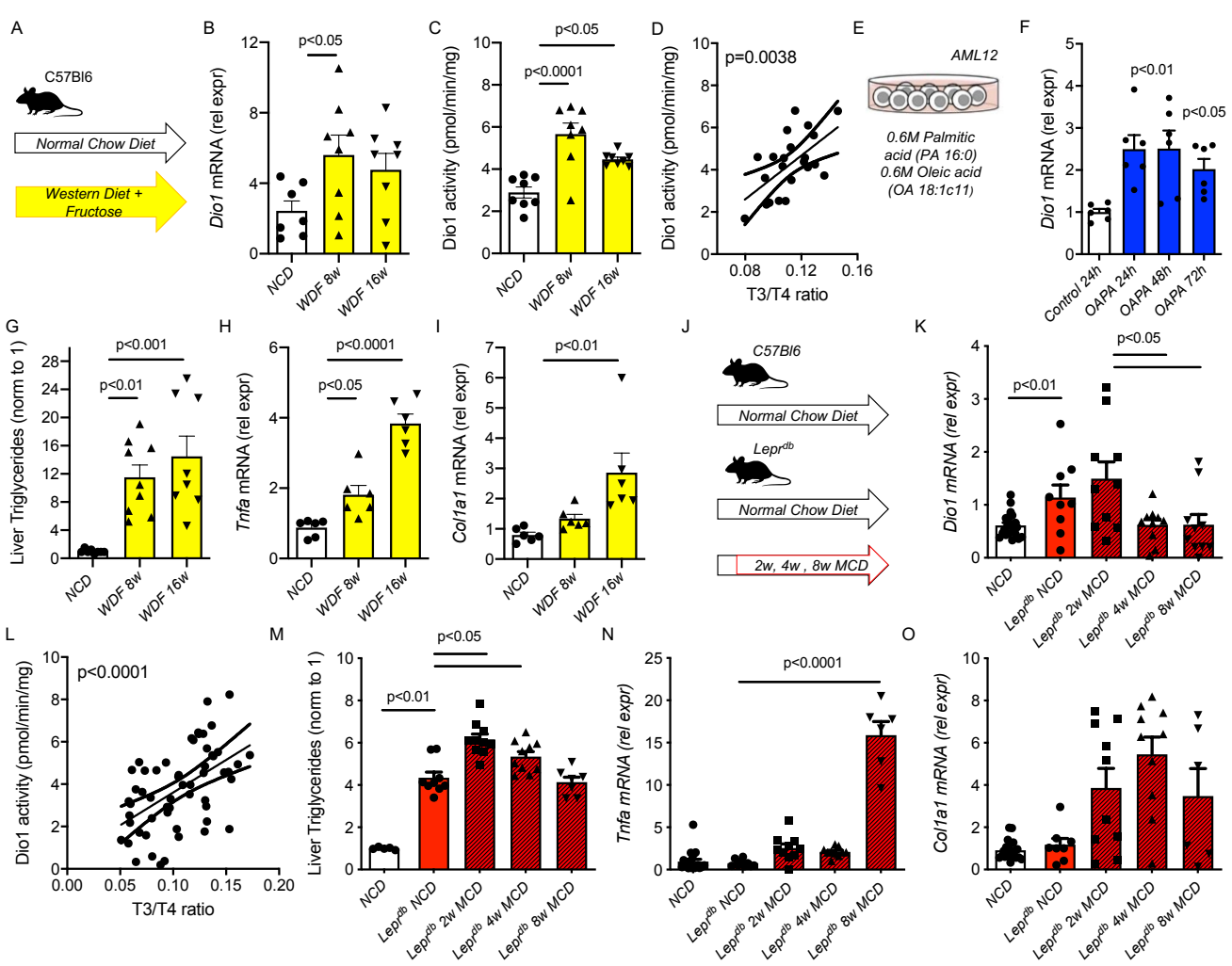

Figure 1. Dio1 increases early during the progression of NAFLD (A) Western Diet with 15\% fructose in the drinking water (WDF) for 8 and 16 weeks compared to Normal Chow Diet (NCD), ( $n=7-8$ per group) (B,C) Dio1 mRNA, DIO1 Activity in the WDF model, (D) Association between Deiodinase 1 activity and liver $T_{3} / T_{4}$ ratio in the WDF model $(E)$ Mouse AML12 cell line with oleic acid and palmitic acid (OAPA) (6 wells per group) (F) Dio1 mRNA in the AML12 OAPA cell model (G-I) Liver triglycerides, Tnfa mRNA and Col1a1 mRNA in the WDF model (J) Lepr ${ }^{\mathrm{db}}$ model with normal chow diet (NCD) or methionine and choline deficient diet (MCD) compared to C57BI6 with NCD diet ( $\mathrm{n}=6-10$ per group) (K) Dio1 mRNA in the Lepr ${ }^{\mathrm{db}}$ model $(\mathrm{K})$ Association between Deiodinase 1 activity and liver $\mathrm{T}_{3} / \mathrm{T}_{4}$ ratio in the Lepr ${ }^{\mathrm{db}}$ model (L-O) Liver triglycerides, Tnfa $m R N A$ and Col1a1 mRNA in the Lepr ${ }^{\mathrm{db}}$ model. Data is depicted in mean \pm SEM. 

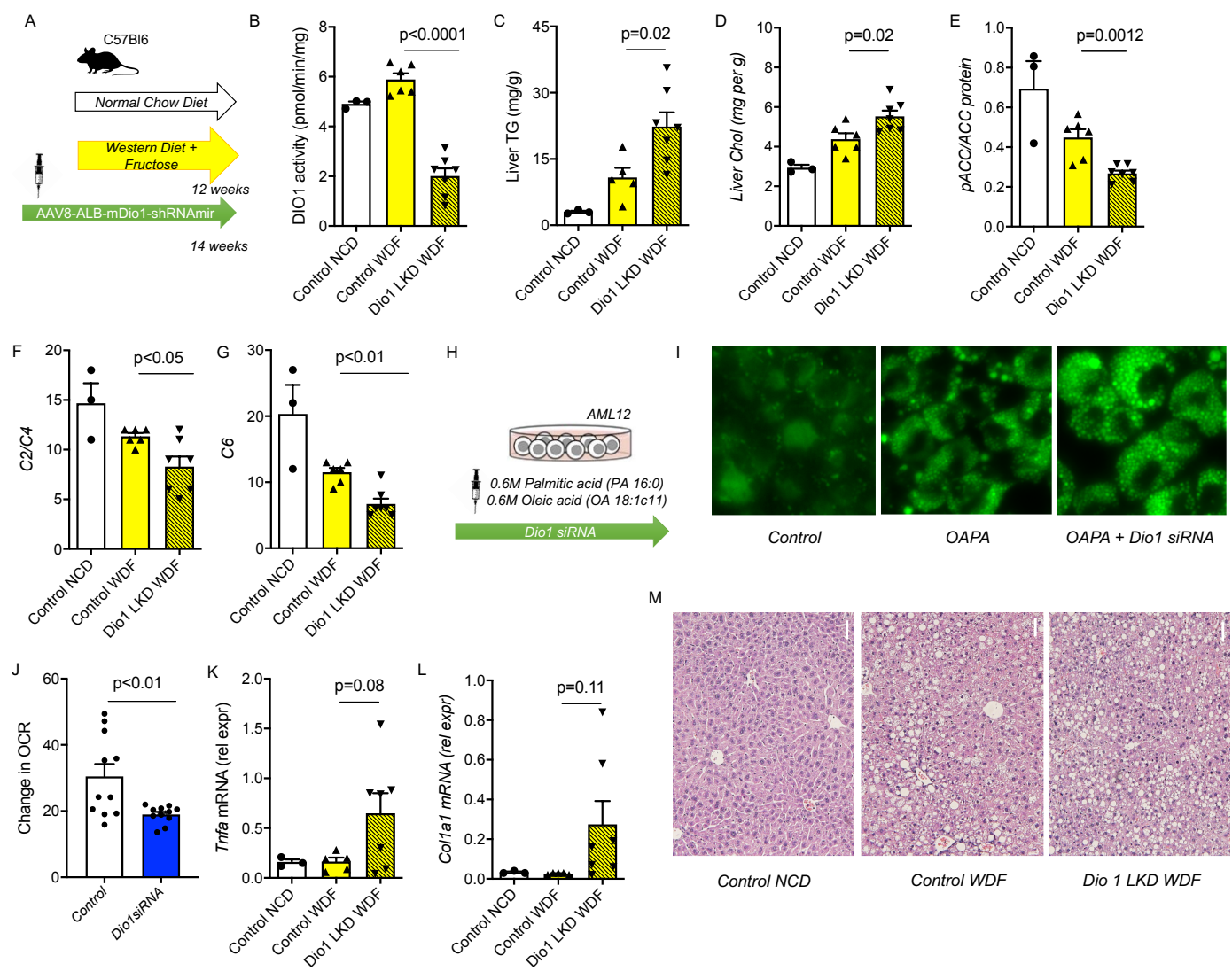

\section{"}

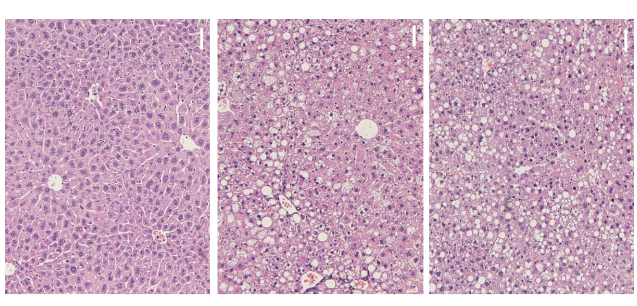

Control NCD

Control WDF

Dio 1 LKD WDF

Figure 2. Dio1 KD increases liver triglycerides and cholesterol. (A) WDF model with injection of AAV8-Albumin-eGFP-mDio1-shRNAmir (WDF + Dio1 LKD) (n=7) or AAV8-Albumin-eGFP-ctrlshRNAmir (WDF + control) $(n=6)$. For reference a group of NCD + control shRNA was included $(n=3)$. (B-G) DIO1 activity (B), liver triglycerides (TG; C), liver cholesterol (D), densitometric quantification of western blots analysing pACC/ACC (E), C2/C4 acylcarnitines (F), C6 acylcarnitines $(G)$ in the WDF Dio1 KD model. $(H)$ Schematic representation of in vitro experiment utilizing mouse AML12 cell line treated with oleic acid and palmitic acid (OAPA) combined with Dio1 siRNA knockdown. (I) BODIPY staining of the AML12 cell line combined with OAPA and OAPA with Dio1 siRNA. (J) Change in oxygen consumption rate (OCR) after Dio1 siRNA in AML 12 cells. (K-L) Tnfa mRNA (K), Col1a1 mRNA (L) in the WDF Dio1 KD model. (M) Histology of control NCD, control WDF, and Dio1 LKD WDF with TG content on average group. Data is depicted in mean \pm SEM. 


\section{Tables}

\begin{tabular}{|c|c|c|c|c|c|c|c|c|}
\hline & \multicolumn{3}{|c|}{ WDF } & \multicolumn{5}{|c|}{$L e p r^{d b}+M C D$} \\
\hline & NCD & $\begin{array}{l}\text { WDF } \\
8 w\end{array}$ & $\begin{array}{l}\text { WDF } \\
16 \mathrm{w}\end{array}$ & $\begin{array}{l}\text { Control } \\
\text { NCD }\end{array}$ & $\begin{array}{l}\text { Lepr }^{\mathrm{db}} \\
\text { NCD }\end{array}$ & $\begin{array}{l}\text { Lepr }^{\mathrm{db}} \\
\text { MCD } \\
2 \mathrm{w}\end{array}$ & $\begin{array}{l}\text { Lepr }^{\mathrm{db}} \\
\text { MCD } \\
4 \mathrm{w}\end{array}$ & $\begin{array}{l}\text { Lepr }^{\mathrm{db}} \\
\text { MCD } \\
8 w\end{array}$ \\
\hline $\begin{array}{l}\text { Liver } \\
\mathrm{T}_{4}(\mathrm{pmol} / \mathrm{g})\end{array}$ & $\begin{array}{l}25.96 \\
(2.20)\end{array}$ & $\begin{array}{l}15.29^{\star * * *} \\
(1.02)\end{array}$ & $\begin{array}{l}15.08^{* * * *} \\
(0.82)\end{array}$ & $\begin{array}{l}29.11 \\
(1.03)\end{array}$ & $\begin{array}{l}17.00^{* *} \\
(1.26)\end{array}$ & $\begin{array}{l}11.22^{\star *} \\
(0.72)\end{array}$ & $\begin{array}{l}12.22^{* \star \star} \\
(0.71)\end{array}$ & $\begin{array}{l}12.46^{* \star \star} \\
(1.31)\end{array}$ \\
\hline $\begin{array}{l}\text { Liver } \\
\mathrm{T}_{3}(\mathrm{pmol} / \mathrm{g})\end{array}$ & $\begin{array}{l}2.66 \\
(0.23)\end{array}$ & $\begin{array}{l}2.09 \\
(0.32)\end{array}$ & $\begin{array}{l}1.69^{*} \\
(0.06)\end{array}$ & $\begin{array}{l}2.25 \\
(0.18)\end{array}$ & $\begin{array}{l}1.99^{* *} \\
(0.09)\end{array}$ & $\begin{array}{l}1.48^{* *} \\
(0.09)\end{array}$ & $\begin{array}{l}1.3^{* * * *} \\
(0.09)\end{array}$ & $\begin{array}{l}1.55^{\star} \\
(0.16)\end{array}$ \\
\hline $\begin{array}{l}\text { Dio3 mRNA } \\
\text { (rel expr) }\end{array}$ & $\begin{array}{l}1.90 \\
(0.42)\end{array}$ & $\begin{array}{l}2.55 \\
(0.71)\end{array}$ & $\begin{array}{l}2.36 \\
(0.39)\end{array}$ & $\begin{array}{l}2.09 \\
(0.28)\end{array}$ & $\begin{array}{l}1.20 \\
(0.29)\end{array}$ & $\begin{array}{l}2.93^{* * *} \\
(0.33)\end{array}$ & $\begin{array}{l}1.64 \\
(0.23)\end{array}$ & $\begin{array}{l}1.16 \\
(0.27)\end{array}$ \\
\hline $\begin{array}{l}\text { Dio3 activity } \\
\text { (fmol/min/mg) }\end{array}$ & $\begin{array}{l}0.20 \\
(0.03)\end{array}$ & $\begin{array}{l}0.14 \\
(0.03)\end{array}$ & $\begin{array}{l}0.15 \\
(0.01)\end{array}$ & $\begin{array}{l}0.13 \\
(0.01)\end{array}$ & $\begin{array}{l}0.05^{\star \star \star \star} \\
(0.01)\end{array}$ & $\begin{array}{l}0.07 \\
(0.01)\end{array}$ & $\begin{array}{l}0.11 \\
(0.03)\end{array}$ & $\begin{array}{l}0.06 \\
(0.02)\end{array}$ \\
\hline Thrb $m R N A$ & $\begin{array}{l}0.97 \\
(0.14)\end{array}$ & $\begin{array}{l}0.94 \\
(0.18)\end{array}$ & $\begin{array}{l}0.67 \\
(0.10)\end{array}$ & $\begin{array}{l}3.21 \\
(0.23)\end{array}$ & $\begin{array}{l}2.46 \\
(0.27)\end{array}$ & $\begin{array}{l}2.66 \\
(0.30)\end{array}$ & $\begin{array}{l}1.94 \\
(0.21)\end{array}$ & $\begin{array}{l}3.86^{*} \\
(0.57)\end{array}$ \\
\hline Mct8 mRNA & $\begin{array}{l}1.07 \\
(0.27)\end{array}$ & $\begin{array}{l}2.72^{* *} \\
(0.43)\end{array}$ & $\begin{array}{l}1.94 \\
(0.22)\end{array}$ & $\begin{array}{l}2.95 \\
(0.32)\end{array}$ & $\begin{array}{l}2.35 \\
(0.44)\end{array}$ & $\begin{array}{l}4.89^{\star} \\
(0.88)\end{array}$ & $\begin{array}{l}2.94 \\
(0.42)\end{array}$ & $\begin{array}{l}6.82^{\star *} \\
(1.34)\end{array}$ \\
\hline Mct10 mRNA & $\begin{array}{l}1.31 \\
(0.36)\end{array}$ & $\begin{array}{l}3.75^{*} \\
(1.01)\end{array}$ & $\begin{array}{l}1.20 \\
(0.26)\end{array}$ & $\begin{array}{l}2.28 \\
(0.38)\end{array}$ & $\begin{array}{l}1.16 \\
(0.19)\end{array}$ & $\begin{array}{l}1.63 \\
(0.34)\end{array}$ & $\begin{array}{l}1.31 \\
(0.37)\end{array}$ & $\begin{array}{l}1.57 \\
(0.33)\end{array}$ \\
\hline
\end{tabular}

Table 1. Liver parameters during the progression of NAFLD in the Western Diet with $15 \%$ Fructose in the drinking water (left) and the Lepr ${ }^{\mathrm{db}}$ model with a methionine and choline deficient diet (MCD) or normal chow diet (NCD) (left). Significance of post-hoc analysis WDF 8w vs NCD and WDF 16 w vs NCD (left panel), Lepr ${ }^{d b}$ NCD vs C57BI6 NCD, Lepr ${ }^{d b} 2$ w, 4 w and 8 w post-hoc analysis vs Lepr ${ }^{d b}$ NCD (right panel). ${ }^{*} p<0.05,{ }^{* *} p<0.01,{ }^{* * *} p<0.001,{ }^{* * * *} p<0.0001$. Data is depicted in mean \pm SEM. 


\begin{tabular}{|l|l|l|l|}
\hline & Control-NCD & Control-WDF & Dio1LKD-WDF \\
\hline $\mathrm{T}_{4}$ liver (pmol/g) & $41.40(4.71)$ & $28.12(2.40)$ & $40.59(2.81)^{\star}$ \\
\hline $\mathrm{T}_{3}$ liver $(\mathrm{pmol} / \mathrm{g})$ & $6.07(1.01)$ & $6.82(1.06)$ & $8.86(2.58)$ \\
\hline $\mathrm{T}_{4}$ serum $(\mathrm{nmol} / \mathrm{l})$ & $62.00(4.04)$ & $52.33(3.73)$ & $72.43(3.09)^{\star *}$ \\
\hline $\mathrm{T}_{3}$ serum (nmol/l) & $1.63(0.05)$ & $1.68(0.15)$ & $1.56(0.10)$ \\
\hline Thrb mRNA & $2.74(0.55)$ & $1.13(0.10)$ & $2.15(0.31)^{\star}$ \\
\hline Mct8 mRNA & $3.67(1.19)$ & $3.15(1.41)$ & $4.36(1.07)$ \\
\hline Mct10 mRNA & $1.23(0.18)$ & $0.64(0.09)$ & $1.20(0.41)$ \\
\hline
\end{tabular}

Table 2. Liver and serum parameters in normal chow diet (NCD) with a control shRNA (controlNCD) and western diet with $15 \%$ fructose in the drinking water (WDF) with a control shRNA (controlWDF) compared to Dio1 liver specific knockdown (Dio1LKD-WDF). Significance is shown for WDF control vs WDF Dio1 LKD. * $p<0.05,{ }^{* *} p<0.01$. Data is depicted in mean \pm SEM. 